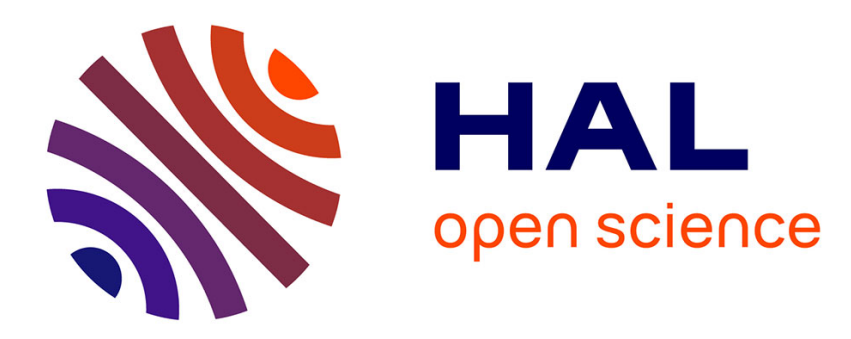

\title{
The absorption band edge of lead telluride films under quantum size effect
}

\author{
A.H. Abou El Ela
}

\section{To cite this version:}

A.H. Abou El Ela. The absorption band edge of lead telluride films under quantum size effect. Revue de Physique Appliquée, 1975, 10 (3), pp.105-108. 10.1051/rphysap:01975001003010500 . jpa00243887

\section{HAL Id: jpa-00243887 https://hal.science/jpa-00243887}

Submitted on 1 Jan 1975

HAL is a multi-disciplinary open access archive for the deposit and dissemination of scientific research documents, whether they are published or not. The documents may come from teaching and research institutions in France or abroad, or from public or private research centers.
L'archive ouverte pluridisciplinaire HAL, est destinée au dépôt et à la diffusion de documents scientifiques de niveau recherche, publiés ou non, émanant des établissements d'enseignement et de recherche français ou étrangers, des laboratoires publics ou privés. 


\title{
THE ABSORPTION BAND EDGE OF LEAD TELLURIDE FILMS UNDER QUANTUM SIZE EFFECT
}

\author{
A. H. ABOU EL ELA $(*)$ \\ National Research Centre, Cairo U. A. R. \\ (Reçu le 22 avril 1974, révisé le 15 octobre 1974, accepté le 16 janvier 1975)
}

\begin{abstract}
Résumé. - La variation de l'absorption optique en fonction de la longueur d'onde a été mesurée pour des couches minces de $\mathrm{PbTe}$. Les effets de taille quantiques dans ces couches sont mis en évidence par des accidents dans ces variations qui reflètent les variations de la densité d'état en fonction de l'énergie et par le décalage du bord de bande vers des énergies supérieures pour des couches d'épaisseur décroissante.
\end{abstract}

Abstract. - The spectral dependence of the optical absorption of $\mathrm{PbTe}$ films is determined under quantum size effect conditions. This dependence is nonmonotonic due to the dependence of the density of states on the energy in size quantized films. The absorption band edge is shifted to higher energies when the film thickness is reduced.

The investigation of thin films is of interest both from the purely scientific point of view and from the practical one, since new specific effects, not observed in the bulk, can appear in the film state. It is known that when the film thickness becomes comparable with the de Broglie wavelength of carriers $(\lambda)$, oscillations in the kinetic and thermodynamic properties of the films occur which are due to the quantization of quasiparticle motion along the normal to the film surface $[1,2]$.

In metals, the de Broglie wavelength is of the order of the lattice period $(\sim 5 \AA)$. Therefore, in actual metallic films containing many atomic layers, quantum size effects (QSE) are weakly pronounced. The situation is different in semimetallic films, since the de Broglie wavelength of the carriers can be larger by several orders of magnitude than the interatomic distances. Most of the experimental investigations of the QSE in films have been carried out on semimetal films, since degenerate current carriers make the oscillatory effect more pronounced. The quantum size effects in bismuth $[3,4]$ and antimony $[5,6]$ were investigated. However, the quantum size effect in semiconductor films is much more favorable and of considerable interest, indeed, since $\lambda \propto \frac{h}{\left(2 m_{n}^{*} K T\right)^{1 / 2}}$ (where $m^{*}$ is the electron effective mass, $T$ is the absolute temperature, $K$ and $h$ are Boltzmann's and Planck's constants) which gives $\lambda \sim 10^{-5} \mathrm{~cm}$. In the case of degenerate semiconductors $m^{*}$ should be replaced by $m^{*} \mu_{\mathrm{f}}$ where $\mu_{\mathrm{f}}$ is the reduced Fermi level [7].

(*) Present address : Al Alwiyah, P. O. B. 2153, Baghdad, Iraq.
The quantum size effect causes the conduction and valence bands to break up into subbands, whose numbers correspond to discrete values of the wave vector along the quantizing dimension of the film. In the case of quantization in an infinitely deep potential well, we have

$$
E_{s}=\frac{\pi^{2} \hbar^{2}}{2 m_{n}^{*} L^{2}} \cdot s^{2}=E_{1} s^{2} .
$$

Where $L$ is the film thickness and $s$ is a discrete quantum number which denotes the serial number of the subband order. Therefore, the effect should appear as an increase of the forbidden bandwidth with the decrease of the film thickness. The quantum size effect in InSb films has been reported [8].

In view of the nonmonotonic dependence of the density of states on the energy in a size-quantized films, we may expect a step like dependence of the absorption coefficient on the photon energy in the fundamental absorption region [7]. The present work reports the appearance of this effect in thin PbTe films.

Lead telluride films were prepared by thermal evaporation in a vacuum of $\sim 10^{-5}$ torr at an evaporation rate of $\sim 30 \AA$ per second from a tungsten foil heater onto quartz plates. The starting material was a $\mathrm{PbTe}$ of nearly stoichiometric composition having electron conductivity with the concentration of free electrons, as determined by electrical measurements, equal to $10^{19} \mathrm{~cm}^{-3}$. The film thickness was determined by a method described elsewhere [9]. The uncertainty in the thickness measurement is less than $\pm 10 \%$. According to electron and $\mathrm{x}$-ray diffraction data, the investigated films are polycrystalline with nearly stoichiometric 
composition and have a pronounced texture. The crystallite size was of the same order as the film thickness $L(L \sim 100-400 \AA)$ i. e., across the thickness the films could be regarded as single crystals.

According to Sandomirskii [1, 10] a quasidiscrete spectrum of carriers can appear in films only if a number of conditions are satisfied. Owing to the scattering of electrons, the quasidiscrete spectrum is partially smeared out. In order for the quasidiscrete character of the spectrum to be maintained, it is necessary that the smearing $h / \tau$ (where $\tau$ is the relaxation time) be smaller than the energy gap between neighboring subbands

$$
\frac{h}{\tau}<E_{s+1}-E_{s} .
$$

If $\tau$ is expressed in terms of the experimentally determined mobility, then from eq. (1) the condition (2) becomes.

$$
\mu_{n}>\frac{2 e L^{2}}{\pi^{2} \hbar(2 s+1)} .
$$

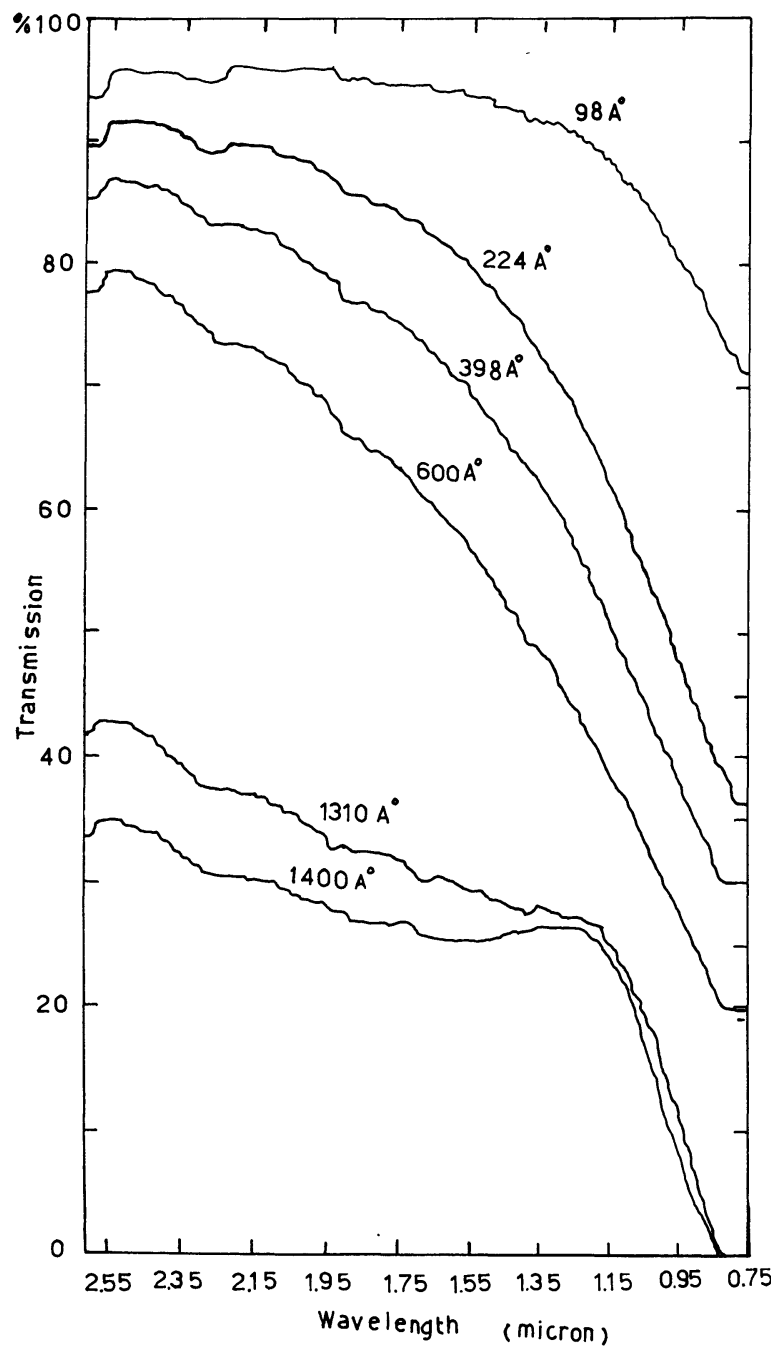

FIG. 1. - Spectral dependence of the optical transmission for PbTe films of thicknesses 98, 224, 398, 600, 1310 and $1400 \AA$.
If the electron mobility is $\mu \sim 4 \times 10^{3} \mathrm{~cm}^{2} \cdot \mathrm{V}^{-1} \cdot \mathrm{s}^{-1}$ the condition (3) is satisfied up to $L \sim 400 \AA$. According to Hall effect measurements the majority carrier density was $n=1-1.1 \times 10^{19} \mathrm{~cm}^{-3}$ and the electron mobility was $\mu=(1.7-3.5) 10^{3} \mathrm{~cm}^{2} . \mathrm{V}^{-1} . \mathrm{s}^{-1}$. Therefore, the above condition is satisfied in the investigated range of film thickness. The condition for temperature, is determined from the requirement that the thermal spread must be small compared with the distance between subbands : $K T<E_{s+1}-E_{s}$, which is satisfied at room temperature.

Measurements of the spectral dependence of the optical transmission were carried out in the energy range $0.30-1.65 \mathrm{eV}$, at room temperature, using an IKS-14 infrared spectrophotometer. Figure 1 shows the spectral dependence of the optical transmission for films of different thickness ( $98 \AA \AA-1400 \AA$ ). In order to investigate the variation of absorption band edge with thickness the spectral dependence of the square of the optical density $D^{2}$ for different films is plotted in figure 2. It is evident from figure 2 that the fundamental absorption edge is shifted in the direction of shorter wavelengths when the film thickness is reduced and a step like dependence of $D^{2}$ on the photon energy is observed.

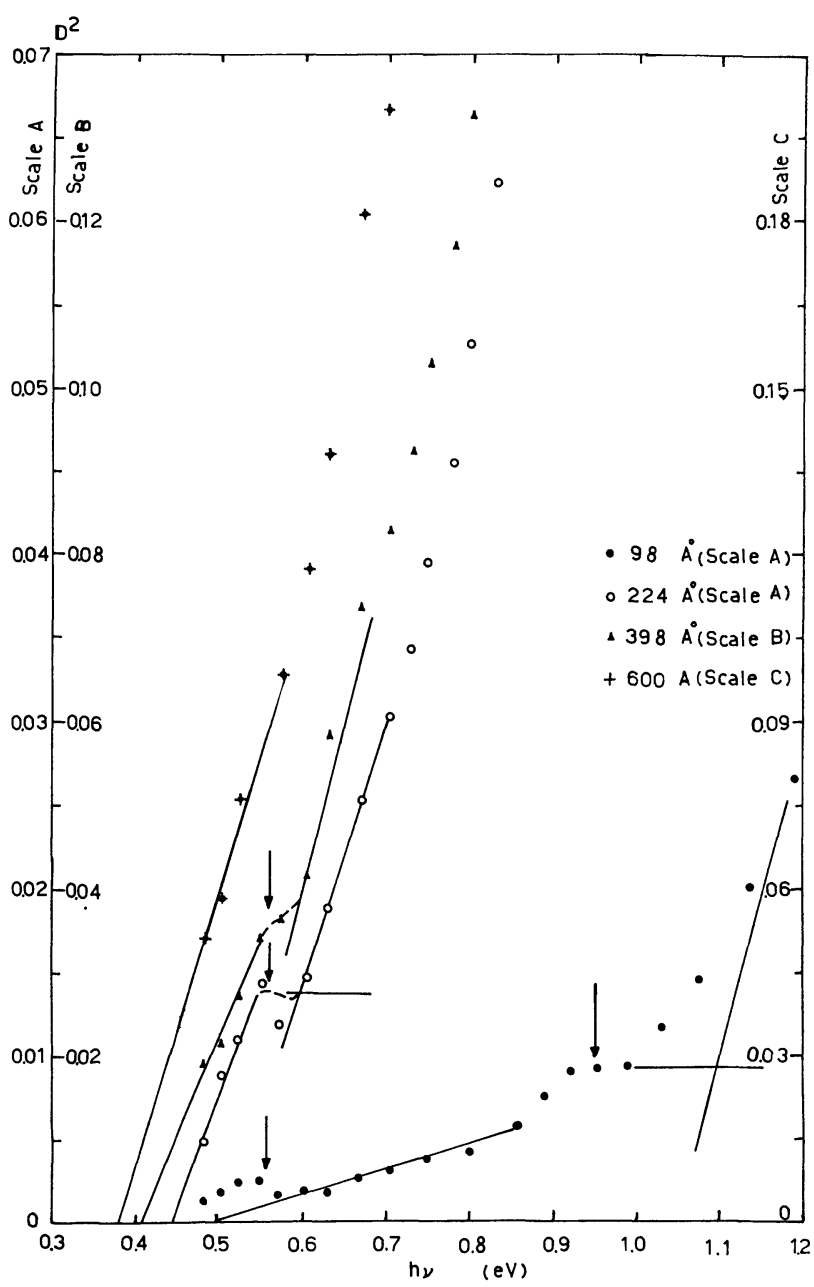

FIG. 2. - Spectral dependence of the square of the optical density for thin PbTe films : 98, 224, 398 and $600 \AA$ thickness. 
The departure from a monotonic spectral absorption curve occurs for thin films only $(L<400 \AA)$. The step like dependence of $D^{2}$ on the photon energy could be correlated with the nonmonotonic energy dependence of the density of states in the conduction band. The steps, indicated by arrows, appear at a slightly different energy values for different thicknesses. Moreover, the $98 \AA$ film thickness exhibited two clearly distinguishable absorption bands. The films $L=224 \AA$ and $L=398 \AA$ had absorption spectra with one step.

Figure 3 shows the variation of the measured absorption band edge $E_{\mathrm{g}}^{\prime}$ (black dots), with the thickness

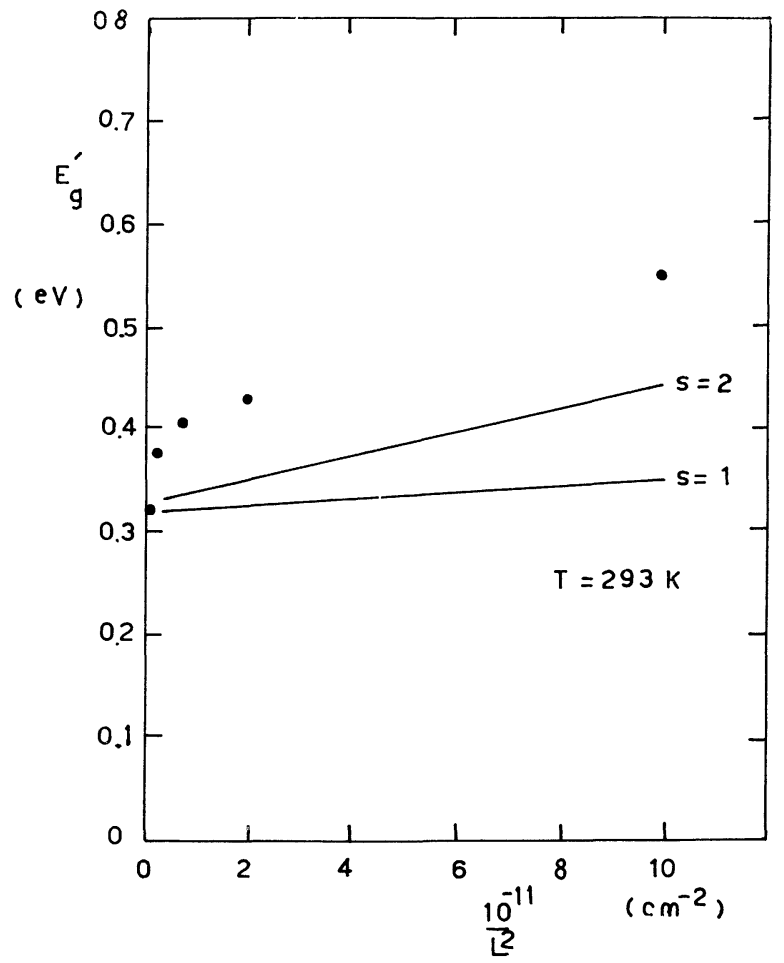

Fig. 3. - The dependence of the absorption band edge on then film thickness : - Experimental values, —— Theoretical curves for $s=1$ and 2 .

(the width of the forbidden band was determined from experimental results by the extrapolation of the dependence of $D^{2}$ on the photon energy at $D^{2}=0$ ). The value of $E_{\mathrm{g}}^{\prime}=0.32 \mathrm{eV}$ obtained for $1400 \AA$ sample at $300 \mathrm{~K}$ agrees with the data reported for the width of the forbidden energy gap of PbTe bulk material at the respective temperature.

The dependence of the absorption band edge of $\mathrm{PbTe}$ films on the thickness can be attributed to the quantum size effect and has no relation to stress effects, since internal stresses resulting from the difference between the thermal expansion coefficients of the film and the substrate give rise to a slight decrease in the forbidden energy gap when the film thickness is reduced [8] which is opposite to the present observation. It is also reasonable to assume that the fine struc- ture of the absorption band edge is also due to the quantum size effect, associated with the nonmonotonic energy dependence of the density of states in the conduction band. Sandomirskii [10] obtained an expression for the density of states, in a thin film, calculated per unit energy interval, in the form

$$
S(E) \mathrm{d} E=\frac{V}{4 \pi^{2}} \frac{\left(2 m_{n}\right)^{3 / 2}}{\hbar^{2}} E_{1}\left(\frac{E}{E_{1}}\right)^{1 / 2} \mathrm{~d} E .
$$

Where $V$ is the normalization volume. With increasing thickness, the density of states at the Fermi level decreases as $1 / L$, so long as the number of filled subbands does not change [1]. However, when a new subband begins to be filled, the density of states increases jumpwise by an amount $S_{\text {sub }}$ (s) this occurs when the energy is altered by an amount $E_{\mathrm{s}}=E_{1} s^{2}$. Consequently, a departure from a monotonic spectral absorption curve can be expected at photon energies given by

$$
h v=E_{\mathrm{g}}+E_{\mathrm{s}}=E_{\mathrm{g}}+\frac{\pi^{2} \hbar^{2}}{2 m_{n}^{*} L^{2}} s^{2} .
$$

where $E_{\mathrm{g}}$ is the forbidden band width of a bulk sample.

It is known that in degenerate n-type InSb the position of the absorption edge is determined not only by the width of the forbidden band $E_{\mathrm{g}}$, but also by the value of the Burstein shift [11] (the increase of the absorption band edge with the electron concentration), which could be considered as a general phenomenon in degenerate n-type semiconductors. Electrical measurements shows that the free carrier concentration remains constant for samples of different thickness. Therefore, the Fermi level and the Burstein shift acquires constant values for all thicknesses. Moreover, expressions (1) and (4) were obtained in the approximation of a rectangular well and of the quadratic dispersion law, however, it has been established that the principal extrema of the energy bands are characterized by a nonparabolic dependence of the energy on the crystal momentum [12]. This means that the effective electron mass in a degenerate material (as determined from magnetic susceptibility measurements, $m^{*}=0.1 \mathrm{~m}_{0} ;$ and from the longitudinal Nernst-Ettinghausen effect, $\left.m^{*}=0.13 m_{0}\right)$ is greater than the mass corresponding to the band minimum $\left(0.06 m_{0}\right)$ [13] and a reduction in the quantum size effect will be expected (in opposite to the Burstein effect). If only the Burstein effect and the band nonparabolicity are considered then the thickness dependence of energy gap will not be observed. The observed shifts are therefore mainly attributed to the quantum size effect. The theoretical dependence of the absorption band edge $E_{\mathrm{g}}^{\prime}$ on $L^{-2}$ calculated from eq. (5) for $S=1, S=2$ and $m^{*}=0.13 m_{0}$, is shown in figure 3 . The deviation of the experimental dependence of $E_{\mathrm{g}}^{\prime}$ on $L^{-2}$ (Fig. 3) from the theoretical curve could be ascribed to the Burstein shift and conduction band non-parabolicity. 


\section{References}

[1] Tavger, B. A. and DemikhovskiI, V. YA., Sov. Phys. Usp. 11 (1969) 644.

[2] LutskiI, V. N., Phys. Stat. Sol. $1 \mathrm{a}$ (1970) 199.

[3] Combet, H. A. and Le Traon, J. Y., Solid State Commun. 6 (1968) 85-87.

[4] Komnik, YU. F. and Bukhshtab, E. I., Sov. Phys. JETP. 27 (1968) 34.

[5] Komnik, YU. F., Bukhshtab, E. I. and Nikitin, YU. V., Sov. Phys. Solid State 12 (1970) 614.

[6] Aвou el Ela, A. H. and Mahmoud, S., Z. Naturforsch. 29a (1974).
[7] Sandomirskir, V. B., Sov. Phys. JETP 16 (1963) 1630.

[8] Filatov, O. N. and Karpovich, I. A., Sov. Phys. Solid State 10 (1968) 2284.

[9] Schoolar, R. B. and Zemel, J. N., J. Appl. Phys. 35 (1964) 1848.

[10] Sandomirskit, V. B., Sov. Phys. JETP 25 (1967) 101.

[11] Burstein, E., Phys. Rev. 93 (1954) 632.

[12] Ravich, YU. I., Efimova, B. A. and Smirnov, I. A., Semiconducting Lead Chalcogenides (Plenum Press, New York) 1970.

[13] Smirnov, I. K., Ukhanov, YU. I., Nensberg, E. D. and Melnik, R. B., Sov. Phys. Semiconductors 3 (1969) 746. 